\title{
Belphégor
}

Littérature populaire et culture médiatique

18-1 | 2020

Regards croisés sur la culture médiatique européenne

\section{Correspondance générale d'Eugène Sue. Volume IV (juin 1850-1854)}

\section{Vittorio Frigerio}

\section{Q OpenEdition}

1 Journals

\section{Electronic version}

URL: https://journals.openedition.org/belphegor/2106

DOI: $10.4000 /$ belphegor.2106

ISSN: 1499-7185

Publisher

LPCM

\section{Electronic reference}

Vittorio Frigerio, "Correspondance générale d'Eugène Sue. Volume IV (juin 1850-1854)", Belphégor [Online], 18-1 | 2020, Online since 04 March 2020, connection on 30 June 2021. URL: http:// journals.openedition.org/belphegor/2106 ; DOI: https://doi.org/10.4000/belphegor.2106

This text was automatically generated on 30 June 2021.

\section{(c) (i) (9)}

Belphégor est mis à disposition selon les termes de la Licence Creative Commons Attribution - Pas d'Utilisation Commerciale - Pas de Modification 4.0 International. 


\section{Correspondance générale d'Eugène Sue. Volume IV (juin 1850-1854)}

\section{Vittorio Frigerio}

\section{REFERENCES}

Correspondance générale d'Eugène Sue. Volume IV (juin 1850-1854). Éditée par JeanPierre Galvan. Paris : Champion, 2018. 670 p. ISBN : 9782745348340.

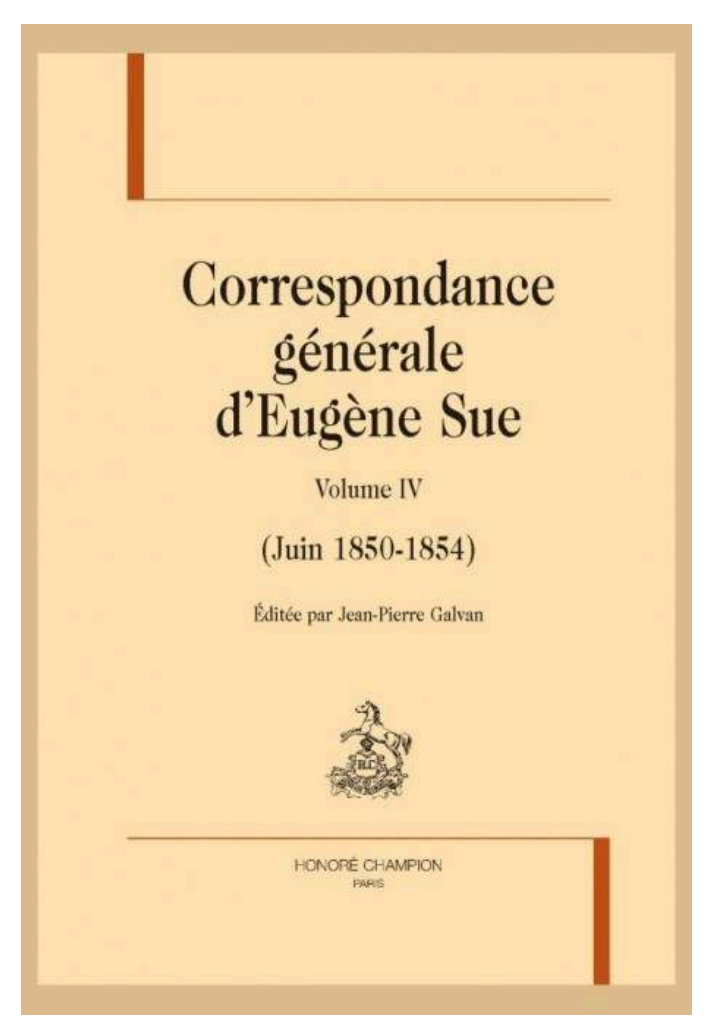


1 Nous avons déjà eu l'occasion de dire le plus grand bien de l'énorme projet mené par Jean-Pierre Galvan avec la publication de la correspondance générale d'un des auteursclef de la littérature française du dix-neuvième siècle - et non pas seulement, comme on a parfois encore coutume de l'affirmer, de la littérature populaire. Ce quatrième et, on présume, sauf découvertes ultérieures, avant-dernier volume, rigoureusement construit et impeccablement présenté, pourvu de notes méticuleuses et riche en petites informations précieuses, mériterait aisément que l'on répète pour lui en les amplifiant tous les compliments qui ont accueilli les volumes précédents. Les années couvertes ici sont parmi les plus importantes pour Sue personnellement, et parmi les plus difficiles et agitées pour le pays. Le romancier, porté par l'immense succès de ses feuilletons, Les Mystères de Paris avant tout, s'est lancé en politique et va entrer à l'Assemblée nationale. Ce sont surtout les années pendant lesquelles Sue, tout en travaillant selon les circonstances et les besoins les plus immédiats, à d'autres romans ou pamphlets, rédige celui qu'il devait considérer comme son ouvrage le plus important, ces Mystères du Peuple dont la portée politique et historique est à ses yeux cruciale. Suite au coup d'état du 2 décembre 1851 l'existence de l'auteur se retrouve bouleversée. Son nom figura-t-il effectivement sur les listes de déportation? Galvan, sur la base des seuls documents disponibles, ne confirme ni n'infirme les bruits qui ont couru à ce sujet. Ce qui est certain, c'est que le romancier fut obligé de se réfugier à Annecy, dans le royaume du Piémont, et que c'est depuis cet exil, entrecoupé de visites en Suisse que supporte de plus en plus mal la police fédérale, qu'il continue son projet d'écriture. Projet qui est un long travail d'éducation du peuple par le biais du feuilleton, véhicule idéal selon lui pour arriver à persuader le lecteur par la magie de la fiction - même alors que celle-ci, comme c'est souvent le cas chez Sue, est abondamment entrelardée de digressions historiques et philosophiques. La production de ces années comprend Jeanne et Louise ou Les Familles des transportés, volume sentimental et anti-bonapartiste, La Famille Jouffroy, roman aux visées déclarément moralisatrices, Clémence Hervé ou La Femme de lettres, dont la publication dans $L a$ Presse est interrompue par la censure, ainsi que des livres que Galvan qualifie de "combat»: Lettres sur la question religieuse et La France sous l'Empire. Ses écrits s'impriment en Angleterre, en Belgique, en Suisse, traversent les frontières, créent du souci pour Massimo d'Azeglio, Premier ministre piémontais et luimême grand romancier historique (auteur notamment de Ettore Fieramosca o La disfida di Barletta), bien plus modéré que Sue, qui aimerait que son hôte encombrant mette de l'eau dans son vin. Chose que celui-ci se trouve par ailleurs de bien des manières obligé à faire, écrivant avec une "extrême réserve " (378) pour pouvoir se ménager un minimum de bienveillance de la part des autorités des États sardes. Discrétion ne signifie toutefois pas oubli de ses principes ou de ce que l'auteur conçoit comme ses devoirs, et le message progressiste de ses œuvres demeure clair à tout lecteur un tant soit peu perceptif. Cela est bien plus nettement le cas d'ailleurs pour Les Mystères du Peuple, qui continuent à paraître en France, «cette œuvre, que les prétentions monarchiques et cléricales, coalisées contre la république démocratique et sociale, rendent presque de circonstance » (131). L'introduction à ce volume reproduit, à juste titre, « la célèbre formule inscrite en exergue à chaque volume [des Mystères du Peuple] : 'Il n'est pas une réforme religieuse, politique ou sociale, que nos pères n'aient été forcés de conquérir de siècle en siècle, au prix de leur sang, par l'INSURRECTION' " (15).

2 S'il est en effet dans ce volume des textes qui présentent un intérêt tout particulier, il s'agit bien des «Lettres aux abonnés » qui accompagnent chaque chapitre du roman, « discours d'accompagnement indispensable à la crédibilisation du contexte historique 
dans lequel se déroule chaque épisode » (17), nous dit Galvan, dans lesquels Sue appuie l'intrigue de fiction sur force citations historiques, pour que ses lecteurs puissent, "pièces en mains» (153), juger du bien fondé de son analyse sociale et pour qu'ils puissent être gagnés à son projet, qui demeure «l'alliance des paysans et des populations des villes, peuple et bourgeoisie, contre la noblesse et la royauté » (403).

Les inconditionnels de Sue, et les dix-neuviémistes plus en général, trouveront sans doute de quoi faire leur miel dans cet épais volume, nouvelle tranche dans la reconstruction d'une vie toute dédiée à la littérature et à l'élévation du peuple. Au-delà de tout raisonnement sur la valeur strictement littéraire de l'œuvre, qui mérite d'autres discours (question que Galvan a d'ailleurs abordée, lui aussi "pièces en mains ", dans son volume sur le premier chapitre des Mystères de Paris paru récemment chez Encrage ${ }^{1}$ ), on découvre ou redécouvre avec plaisir et intérêt au fil de cette correspondance à la fois l'époque et l'homme, personnage attachant, honnêtement et fermement persuadé de l'importance et de l'utilité de son travail, profitant bien peu dans son exil savoyard, financièrement parlant, de sa popularité, mais qui n'en déclarait cependant pas moins : « je suis désormais quant à moi décidé non seulement à autoriser mais à solliciter toute traduction ou reproduction, sans demander un centime pour cela » (551, lettre à l'éditeur Jules Hetzel). Chapeau, posthume, à Sue, et chapeau à son patient biographe pour ce nouveau jalon important dans l'étude du parcours de cet auteur encore de nos jours passionnant.

\section{NOTES}

1. Galvan, Jean-Pierre. Eugène Sue et ses "Mystères ». Un manuscrit inédit des premiers chapitres des «Mystères de Paris». Amiens: AARP - Centre Rocambole, Encrage Édition, 2018. 141 p. ISBN : 9782360580880 . 